\title{
AULA FLUI? \\ DOCÊNCIA E CONDIÇÕES PEDAGÓGICAS NO ATUAL CENÁRIO DA EDUCAÇÃOO
}

\author{
Denise Santiago Feitoza ${ }^{1}$ \\ Edilane Carvalho Teles ${ }^{2}$ \\ Maria Radilene Lopes Gomes ${ }^{3}$
}

\begin{abstract}
Resumo
O presente artigo tem como objetivo refletir sobre a docência e as práticas pedagógicas com as aulas remotas, vistas as limitadas e desafiadoras condições formativas, laborais e de acessos das/os professoras/es durante a pandemia do Covid-19, para a efetivação e continuidade dos processos de ensino e aprendizagem. Para tanto, parte de observações e escuta nos contextos das atuações docentes com os ensinos (básico e superior), para individualizar e refletir os percursos implementados. De metodologia qualitativa, o estudo busca conhecer os modos como essa experiência é compreendida pelos docentes, de acordo com as respostas de um questionário, para a construção de uma análise pautada na hermenêutica filosófica, quanto às realidades e discursos do cenário educacional hodierno.
\end{abstract}

Palavras-chave: Docência. Condições pedagógicas. Educação básica e superior. Pandemia.

\section{TEACHING AND PEDAGOGICAL CONDITIONS IN THE CURRENT EDUCATION SCENARIO}

\begin{abstract}
This article aims to reflect on teaching and pedagogical practices with remote classes, given the limited and challenging training, work and access conditions of teachers during the Covid-19 pandemic, for effectiveness and continuity teaching and learning processes. Therefore, it starts from observations and listening in the contexts of teaching actions with teaching (basic and higher), to individualize and reflect the paths implemented. With a qualitative methodology, the study seeks to understand the ways in which this experience is understood by teachers, according to the answers to a questionnaire, for the construction of an analysis based on philosophical hermeneutics, regarding the realities and discourses of today's educational scenario.
\end{abstract}

Keywords: Teaching. Pedagogical conditions. Basic and higher education. Pandemic.

\footnotetext{
1 Especialização em Gestão e Coordenação pela Universidade de Pernambuco, Brasil (2018). Coordenador de polo da Universidade Aberta do Brasil. Mestranda do PPGESA - Pós-graduação em Educação, Cultura e Territórios Semiáridos, DCH III/UNEB.

${ }^{2}$ Docente do curso de Pedagogia da Universidade do Estado da Bahia (UNEB), Campus III. Doutora em Comunicação pelo Programa de Pós-graduação em Ciências da Comunicação (PPGCOM/ECA/USP) / Área de concentração III: Interfaces Sociais da Comunicação. Docente permanente do PPGESA.

${ }^{3}$ Especialização em Ensino de Língua Portuguesa pela Universidade Candido Mendes, Brasil (2016). Professora da Secretaria de Educação do Estado da Bahia. Mestranda do PPGESA - Pós-graduação em Educação, Cultura e Territórios Semiáridos, DCH III/UNEB
} 


\title{
FLUJOS DE CLASE? \\ CONDICIONES DIDÁCTICAS Y PEDAGÓGICAS EN EL ESCENARIO EDUCATIVO ACTUAL
}

\begin{abstract}
Resumen
Este artículo tiene como objetivo reflexionar sobre las prácticas docentes y pedagógicas con clases a distancia, dadas las limitadas y desafiantes condiciones de capacitación, trabajo y acceso de los docentes durante la pandemia Covid-19, para la efectividad y continuidad de los procesos de enseñanza y aprendizaje. Por tanto, se parte de la observación y la escucha en los contextos de las acciones docentes con la docencia (básica y superior), para individualizar y reflejar los caminos implementados. Con una metodología cualitativa, el estudio busca comprender las formas en que esta experiencia es entendida por los docentes, de acuerdo con las respuestas a un cuestionario, para la construcción de un análisis basado en la hermenéutica filosófica, sobre las realidades y discursos del escenario educativo actual.
\end{abstract}

Palabras llave: Docencia. Condiciones pedagógicas. Educación básica y superior. Pandemia.

\section{Introdução}

Este estudo é um convite à reflexão docente sobre a prática pedagógica, relacionada à formação contínua e as condições encontradas hoje, incluindo os meios utilizados nas ações implementadas com o ensino remoto. Assim, inicia destacando que não é suficiente apontar que o contexto é de muita complexidade e que é preciso criar, promover e possibilitar percursos que viabilizem a educação, para auxiliar e até propor outros/novos processos teórico-metodológicos de melhores condições de trabalho e de qualidade à educação. A questão vem ganhando maior ênfase nos contextos, principalmente pelas ausências e dificuldades que encontramos em diferentes níveis: de formação, técnica e tecnológica, institucional e, na base de tudo, a política que incide nos processos e nas relações humanas.

Isto posto, os diversos formatos de ensinos remotos (ER's) - pois cada um realiza ao próprio modo - emergiram como alternativas e abordagem para os processos de ensino-aprendizagem, que foram justapostos às modalidades de ensino recorrentes, em prol da população que está/estava (ou não) resguardada em suas casas e que necessitava dar continuidade ao desenvolvimento educacional, individual, coletivo e profissional dos sujeitos integrantes, deste complexo emaranhado de sentimentos e acontecimentos.

Nesse contexto, as emoções têm exigido mais atenção que os próprios fatos e acontecimentos, daí as confusas ordenações/orientações sobre os construtos quanto às 
prioridades do fazer educacional no país, o quê evidenciou de forma abissal as diferenças excludentes entre o ensino público e privado, educação básica e superior, estados e regiões, educação nas zonas urbanas e dos/nos campos. Ou seja, analisar e refletir o cenário da educação de hoje tem se constituído um problema sem fim, por isso a proposta desta pesquisa e escrita, que possa somar a outras tantas, num mote de denúncia e reivindicações por uma educação pública, igualitária e de qualidade para todos.

No cenário que se forma, a preocupação do cômputo da carga horária do ano letivo trouxe através da aprovação pelo Conselho Nacional de Educação do Ensino

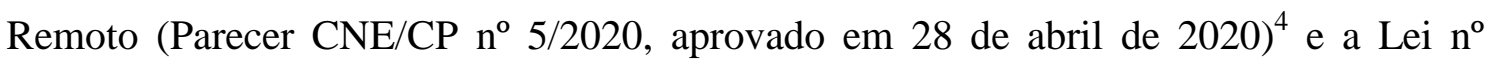
$14.040^{5}$, a necessidade de adaptação e de metodologias diversas daquelas secularmente habituadas no ensino presencial, as quais tiveram nos últimos tempos, demandas por outros formatos e modalidades. Os documentos não são suficientes para dar conta das problemáticas nos contextos com o ER, assim, destacamos: a) a pesquisa e a práxis para conhecer e propor metodologias mais 'ativas', como uma das possibilidades para repensar e superar a abordagem tradicional e exclusivamente presencial, como meio de ensino e aprendizagem; b) as formações continuadas a serem priorizadas e organizadas para/pelas instituições responsáveis da Educação no país, públicas e privadas, de forma mais igualitária e justa, bem como a valorização da profissionalização docente em seu âmbito individual e coletivo nos espaços de trabalho; c) compreender que a complexidade das ações implementadas no momento da pandemia têm se configurado cada vez mais, num problema de não retorno aos modos como a educação era realizada, e que as ausências do estado, da sociedade civil e das instituições neste período na tomada de decisões mais ágeis e incisivas para todos, podem (já estão!) comprometer a educação dos anos vindouros e o direito à educação. Esse último tópico é gravíssimo!

Para refletir as proposições acima, abordaremos em três direcionamentos: 1) os significados da docência e as condições pedagógicas que as/os professoras/es têm encontrado para dar continuidade às ações; 2) o atual cenário da educação e os desafios a serem superados, incógnitas que precisam ser postas nos centros das discussões e

\footnotetext{
http://portal.mec.gov.br/index.php?option=com_docman\&view=download\&alias=14511-pcp00520\&category slud=marco-2020-pdf\&Itemid=30192 Acesso em 10 de jun 2021.

${ }^{5}$ De 18 de agosto de 2020, que estabelece normas educacionais excepcionais a serem adotadas durante o estado de calamidade pública.
} 
ações dos docentes com o estado e a sociedade civil, partindo da escuta e observação das realidades nos contextos; 3) promover e construir novas/outras experiências, para lidar com um processo que não podemos vislumbrar um fim, pois ainda não alcançamos a superação da pandemia.

\section{Docência e condições pedagógicas}

O que vivemos, não são tempos normais! Quem compreende e vive os problemas que acarretam a pandemia não tem tranquilidade e, a educação, entre todas as instituições, está longe de encontrar um mínimo de normalidade para que seu funcionamento chegue a todos (sequer chegou à maioria ${ }^{6}$ ), com o respeito que merece. Não saber o que está por vir, bem como, não ter conhecimentos de políticas públicas, das decisões ministeriais e secretarias de educação, para a superação do 'fosso' que se encontra a educação brasileira, angustia e muito!

O que tem sido feito, em relação aos docentes é o registro e a definição de uma experiência elaborada e construída na emergência; embasadas na necessidade de feedbacks, devolutivas, associadas a estudos e pesquisas; assim como em proposições feitas para além do tempo de trabalho, cuja carga horária que já era exaustiva antes da pandemia se intensificou ainda mais.

Isto posto, nos traz a reflexão sobre a responsabilidade da educação exclusivamente sobre os docentes, quando o Estado e as instituições não criam estruturas e condições materiais e imateriais para a continuidade das ações formativas. A citar, alguns exemplos amplamente vistos:

1) a continuidade do ensino para as instituições privadas e a 'longa 'espera do início/reinício das aulas nas instituições públicas, destacam-se os não acessos e a ausência/presença das más condições econômicas e sociais dos estudantes, questionando dessa forma a atuação e a assistência que as ações das esferas do Estado (Federal, Estadual e Municipal) garantem para a educação das maiorias, como no caso da escola pública. Verifica-se a exiguidade de um maior investimento em internet e equipamentos, fato que incomoda e inquieta;

${ }^{6}$ A 'maioria' que nos referimos no texto significa os estudantes da Escola pública. 
2) as dificuldades de acessos, cuja internet brasileira não dá conta para os que podem pagar, menos ainda, para os que estão fora dessa inclusão, que hoje é um direito e não um privilégio;

3) a exigência da sociedade, instituições e pais, de que os professores continuassem, sem contudo, promover acompanhamento formativo e de tecnologias necessárias, com raras exceções, como equipamentos, internet e formação, que ficaram a 'cargo 'das/os professoras/es, incluindo ainda, o custo do trabalho como investimento financeiro próprio;

4) os modos diversos de planejamentos em muitos contextos e segmentos aleatoriamente, nos desafiando ao reconhecimento e a necessidade de compartilhamento, investigação e socialização com os meios, para colaborar com as docências e a práticas que promovem;

5) por fim, as sistematizações dos modos como ampliar as compreensões do presente, para vislumbrar reflexões que possam nos ajudar nas etapas atuais e nas seguintes, com qualidade.

A seguir, são abordadas as respostas dadas por professoras/es de diversos segmentos de ensino, que colaboraram respondendo ao questionário que realizamos no âmbito do grupo de pesquisa ${ }^{7}$, com questões abertas para que pudessem escrever e nos 'contar', por assim dizer, as dificuldades, problemáticas e experiências desse período.

\section{Percurso de investigação: a análise dos dados}

A metodologia utilizada é de viés qualitativo, propondo uma abordagem que mesmo em distância, pudéssemos conhecer o que pensam e como atuam os docentes com o ER. Assim, foi proposto um questionário construído no Google forms, distribuído através das redes, de participação voluntária, com perguntas em sua maioria abertas, para que os colaboradores pudessem se expressar, ao próprio modo, sobre as dificuldades e experiências que têm vivido. A proposta é de um estudo que busca conhecer os modos como essas são construídas e compreendidas.

Para interpretar as respostas, a análise foi pautada na hermenêutica filosófica, como percurso de investigação e referência para a compreensão, autocompreensão,

\footnotetext{
${ }^{7}$ Grupo de Pesquisa Polifonia - Observatório de Educação e Comunicação, do Departamento de Ciências Humanas, Campus III, da Universidade do Estado da Bahia (UNEB) 
crítica e autocrítica, pois ao mesmo tempo que somos idealizadoras da pesquisa, somos ainda docentes, portanto, implicadas e imbricadas como o campo. O percurso foi sistematizado da seguinte forma:

- Definição das categorias de pesquisa para a presente escrita e entendimentos do objeto;

- Escolha entre as questões propostas, as que possuem convergências com o objetivo a ser sistematizado e socializado;

- Individualização e interpretação das respostas, relacionando as categorias;

- Escolha dos discursos expressos nas escritas que podem subsidiar as análises e reflexões.

Como opção metodológica, a hermenêutica propõe o entendimento do percurso de investigação no campo educacional (CIAN, 1997), como uma ampliação à compreensão e análise das criações de outros/novos caminhos para a realização e 'renovação' da práxis pedagógica. Assim, amplia as possibilidades interpretativas, efetivadas com uma rigorosa delimitação dos modos de realização, pois se propõe ainda, como uma abordagem que na pedagogia é submetida à multiplicidade dos modos e formatos do fazer, por assim dizer, mais dinâmicos, em especial, pela presente pluralidade de 'pontos de vistas', bem como, das construções promovidas pela linguagem. Para tanto, possui alguns aspectos comuns aos fenomenológicos, como (IDEM): a) a tentativa de pensar a educação em um modo 'novo', cujas origens estão pautadas nas ideias husserliana do mundo da vida; b) toma como referência e consideração, a experiência como lugar de desenvolvimento do processo formativo, encontrando no imbricamento teórico-prático, os processos em ação, cujo movimento é de 'reflexão operativa'. Agir na cotidianidade da práxis pedagógica que 'ilumina-se' pela teoria; c) o envolvimento das/os pesquisadoras/es e formadoras/es, proposição também encontrada a pesquisa participante; d) a relação de imbricamento da subjetividade e objetividade; e) o sentido da humildade que caracteriza a escuta na condição da "epoche" hursseliana (IBIDEM) que propõe a suspensão de juízo para poder refletir, sugerindo a construção de um percurso 'coerente' para a interpretação das mensagens expressas nos textos ou como é o caso do processo de formação, dos construtos dos sujeitos, das experiências, dos espaços e da comunidade. Compreendendo que “[...] a verdade não se dá somente no método, o percurso se 
reveste com elementos carregados de interpretação que não exclui o processo histórico."

(TELES, 2019, p. 53)

Como afirmava Gadamer (2001, p. 527, tradução nossa),

O fato de que a experiência hermenêutica tenha o modo de ser da linguagem, que entre a tradição e o intérprete tenha lugar o diálogo, fornece uma base muito diversa e nova. Nem a consciência do intérprete é dona daquilo que, como palavra da tradição, lhe é dirigida, nem se pode descrever adequadamente aquilo que de tempos em tempos nos é comunicado a partir da totalidade da tradição. Com respeito ao intérprete, acontecer significa aqui que ele não escolhe um determinado "objeto" para "dar conta", com determinados métodos, de modo a estabelecer o que um certo texto entende ou o que um determinado evento realmente era, mesmo superando-o, não intransponíveis, dificuldades decorrentes de seus preconceitos pessoais. Este é apenas um aspecto externo do evento hermenêutico, o que justifica a disciplina metódica que o intérprete deve impor-se. ${ }^{8}$

Para a interpretação e análise foram individualizadas três (3) categorias: as práticas pedagógicas e o ER, as condições formativas e laborais e, os processos de ensino-aprendizagem. Todas complexas na composição escrita dos termos/palavras, mas que não podem ser reduzidas, por conta do percurso investigado que é extenso e possui muitas nuances, princípios e dimensões. Assim, relacionado a estes, foi proposto o seguinte percurso: os significados da docência e condições pedagógicas no atual cenário da educação, identificando os desafios a serem superados, conhecendo, criando e sistematizando as novas/outras experiências. Não foi possível neste artigo abordar todas as questões, proposições e discursos que emergiram das respostas de 54 (cinquenta e quatro) docentes que colaboraram com a pesquisa, exigindo desdobramentos futuros.

\section{Sobre as respostas dos docentes}

\footnotetext{
${ }^{8}$ Il fatto che l'esperienza ermeneutica abbia il modo di essere del linguaggio, che fra la tradizione e l'interprete abbia luogo un dialogo, fornisce una base del tutto diversa e nuova. Né la coscienza dell'interprete è padrona di ciò che, come parola della tradizione, le si rivolge, né si può descrivere adeguatamente ciò che di volta in volta può venirci comunicato dalla totalità della tradizione. Rispetto all'interprete, accadere significa qui che egli non si sceglie un certo "oggetto" di cui "venire a capo" con determinati metodi, in modo da stabilire che cosa un certo testo intende o che cosa un certo evento davvero è stato, sia pure vincendo le, non insormontabili, difficoltà derivate dai suoi personali pregiudizi. Questo è solo un aspetto esteriore dell'evento ermeneutico, che giustifica la disciplina metodica che l'interprete deve imporsi.
} 
Dos respondentes, $86,8 \%$ são da rede pública de ensino, 9,4\% privada e os demais, ambas ou filantrópica; De regiões e cidades diferentes: Nordeste (Bahia: Juazeiro e Salvador); Paraíba (Campina Grande); Pernambuco (Afrânio, Trindade, Belém de São Francisco e Petrolina); Norte (Rondônia: Porto Velho); Sudeste (São José da Barra (RJ), Rio de Janeiro, São Paulo); Sul (Florianópolis, Flores da Cunha e São José). Que atuam em diversos segmentos (Gráfico 1).

Gráfico 1 - Segmentos de ensino que atuam os colaboradores.

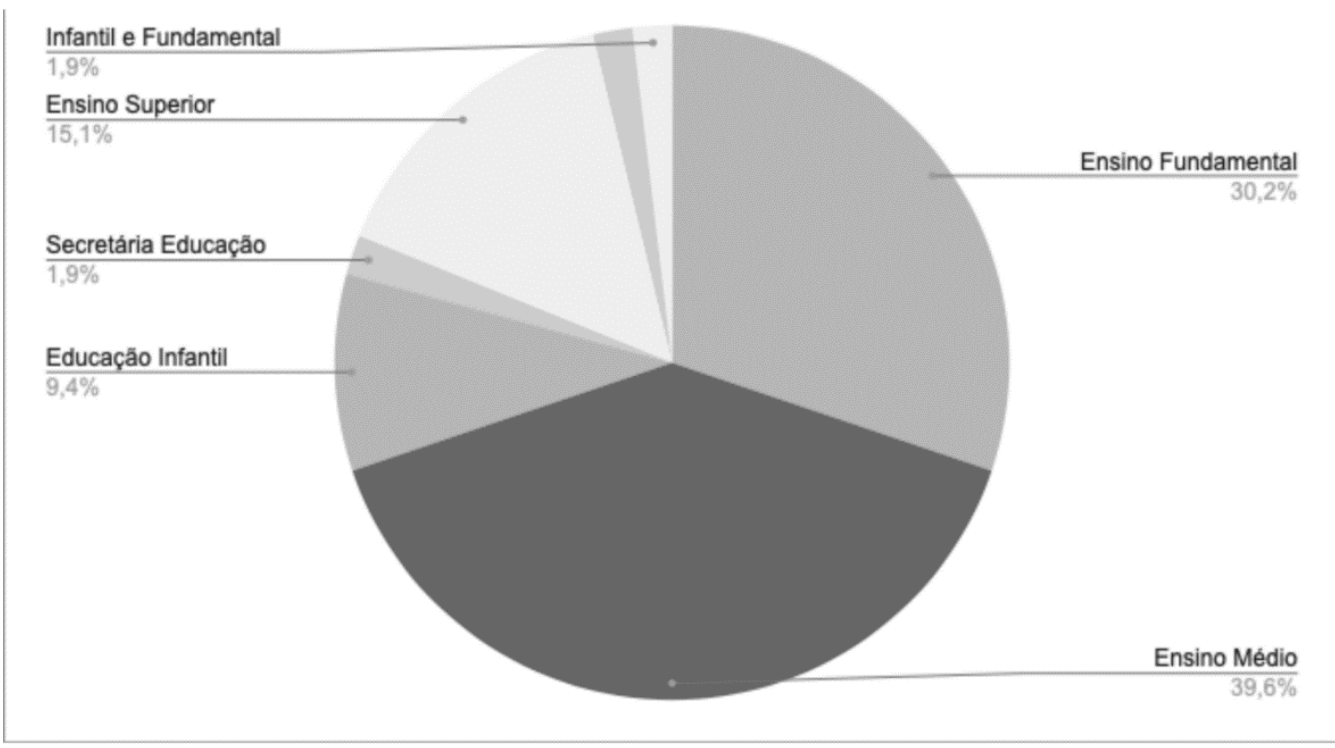

Fonte: As autoras.

Para este estudo selecionamos três (3) das questões do formulário, para a composição dos primeiros entendimentos sobre as categorias definidas com as problemáticas elencadas pelos colaboradores: 1) Quais as principais dificuldades que tem encontrado com o ensino remoto? 2) Qual sua opinião a respeito do aproveitamento das aulas no Ensino Remoto? 3) Como define sua experiência com aulas remotas? Se possível, justifique.

A etapa seguinte foi realizada no wordcloud $^{9}$, para a individualização das palavras, termos e/ou conceitos mais repetidos pelos colaboradores. Como o discurso 
não pode ser fechado em limites rígidos, ao contrário, pois é movediço, complexo e cheio de nuances, optou-se por escolher as 20 primeiras mais citadas, abaixo elencadas na tabela (1) e apresentadas nas figuras/nuvens de palavras (Figura 1, 2, e 3).

Tabela 1 - Quantitativo das palavras que mais aparecem nas respostas dos docentes

\begin{tabular}{|c|c|c|c|c|c|}
\hline \multicolumn{2}{|r|}{ Questão 1} & \multicolumn{2}{|r|}{ Questão 2} & \multicolumn{2}{|r|}{ Questão 3} \\
\hline 42 & alunos & 32 & aproveitamento & 16 & alunos \\
\hline 35 & Acesso / internet & 21 & alunos & 15 & aprendizagem \\
\hline 11 & Falta & 14 & aprendizagem & 12 & experiência \\
\hline 10 & Participação & 12 & aulas & 10 & aula \\
\hline 9 & Atividades & 10 & acesso & 10 & contato \\
\hline 7 & aulas & 7 & ensino & 9 & desafio \\
\hline 7 & equipamentos & 6 & baixo & 9 & estresses \\
\hline 6 & atenção & 6 & defasagem & 9 & várias \\
\hline 5 & aprendizagem & 6 & necessário & 8 & nova \\
\hline 4 & interface & 6 & participação & 8 & Superação \\
\hline 4 & professores & 5 & Dedicados & 7 & ensino \\
\hline 3 & desinteresse & 5 & metodológicas & 7 & presencial \\
\hline 3 & estratégias & 5 & práticas & 6 & contexto \\
\hline 3 & Excesso & 5 & Remoto & 6 & desconhecimento \\
\hline 3 & Família & 4 & Modalidade & 6 & dificuldades \\
\hline 3 & frequência & 4 & positivo & 6 & modalidade \\
\hline 3 & Limitações & 4 & pouco & 6 & possibilidades \\
\hline 3 & Motivar & 4 & prejuízo & 6 & reinventar \\
\hline 3 & Remoto & 3 & Acompanham & 5 & adaptação \\
\hline 2 & adequação & 3 & adaptaram & 5 & conseguir \\
\hline
\end{tabular}

Fonte: As autoras.

Figura 1 - Dificuldades que tem encontrado com o ensino remoto 


\section{CreomSertōes}

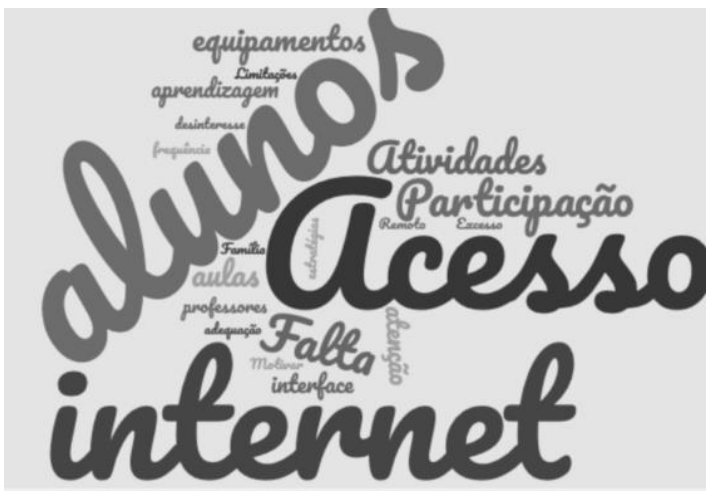

Fonte: As autoras.

\section{Imagem 2 - Aproveitamento das aulas no Ensino Remoto}

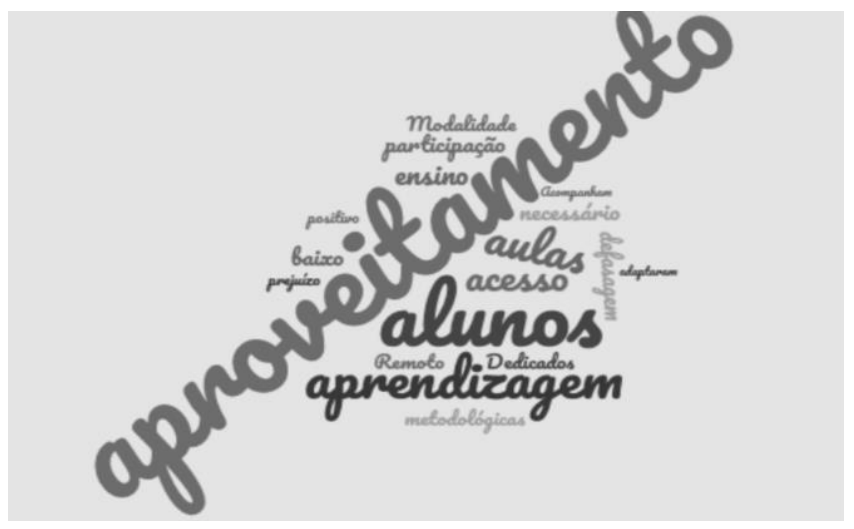

Fonte: As autoras

Imagem 3 - Experiências com aulas remotas

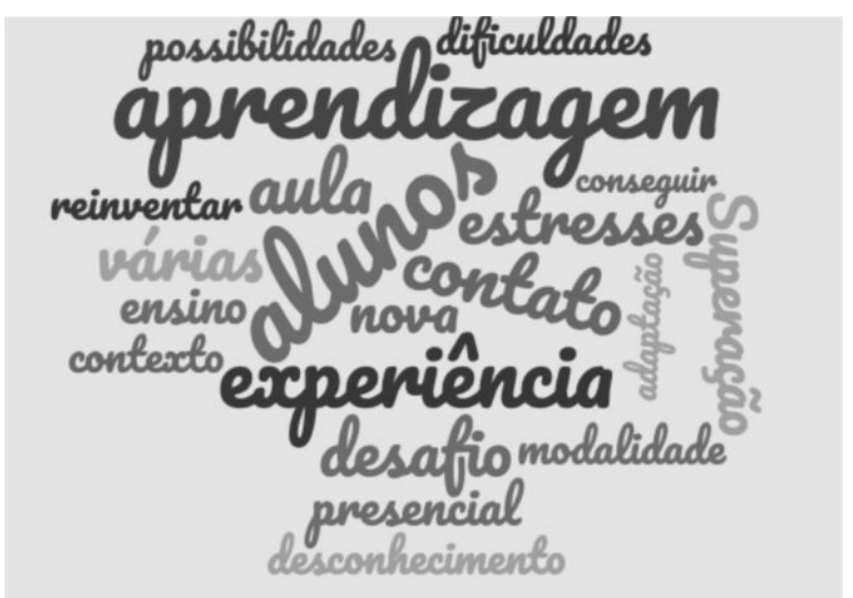

Fonte: As autoras.

As figuras acima expressam em tamanho mais evidente, como visto na tabela, as palavras/termos evidenciados em constância e maior número de vezes. 


\section{- Questão 1}

Sobre as principais dificuldades que têm encontrado com o ER, destacamos quatro aspectos que consideramos em convergência para a análise das respostas, a saber: 1) Alunos sem interesse e/ou dificuldades de usos das TIC's; 2) Problemas de acessos e ausência de acompanhamento; 3) Formação continuada, atuação docente, recursos materiais e imateriais. De acordo com o levantamento feito e a equivalência das respostas dadas, apenas duas foram dissonantes: uma, que afirma não ter "Nenhuma" dificuldade e, a outra que atribui aos dois grupos (docentes e discentes) " $A$ aceitação pelos prof, alunos e, principalmente, os responsáveis dos alunos." Ou seja, considera que ainda não houve aceitação do formato.

No primeiro agrupamento e comparativo sobre o tópico Alunos sem interesse e/ou dificuldades de usos das TIC's, um dos principais problemas é a 'não-adaptação' dos discentes, com 15 respostas, aproximadamente 27,8\%. Abaixo, alguns exemplos:

- $\quad$ "A nossa cultura, que é estudar por obrigação, ou seja, quando não há esse requisito de frequência, o aluno simplesmente se abstém. Além disso, a dificuldade de alguns alunos em aprender através dessa modalidade, sem a presença do professor em sala."

- "Alunado sem interesse nos estudos."

- "Autonomia dos alunos, muitos ainda não desenvolveram, o que enfraquece o processo, uma vez que nesse formato de aulas remotas, exige bastante, uso das TDIC's também, tanto por parte de nós professores quanto por parte dos alunos. Muitos só sabem manusear as redes sociais, quando é para utilizar, word, power point, Excel, por exemplo, não sabem. Uma vez que são ferramentas necessárias para formatação de um trabalho/texto/apresentação, etc."

- $\quad$ "Evasão, desinteresse, não conhecimento total do público estudantil. Presencialmente a gente conhece mais os alunos e não temos tantas desculpas para a falta de atividade entregue. No remoto, além das desculpas, por mais que a gente use de artifícios, nem sempre eles estão prestando atenção ou focados."

- $\quad$ "Baixo número de estudantes com acesso à internet e falta de equipamentos para trabalhar."

• " "Participação dos alunos na vídeo conferência pelo Applique-se ${ }^{10}$.",

Os docentes destacaram como uma das principais dificuldades, o constante desinteresse discente, que não participam de todas as atividades, assim, se havia o problema da participação de muitos estudantes anteriormente à pandemia, agora, essa percepção persiste e amplia. O tópico a seguir, de certa forma justifica por que essa participação e evasão é maior do que a esperada.

${ }_{10}$ Aplicativo de ensino remoto da rede estadual fluminense.

ComSertões, Juazeiro, Bahia, v. 9, n. 1, p. 16-36, ago. 2021 
Como as pesquisas recentes (TELES; CAMPANA; COSTA; NASCIMENTO, 2020), assim como a observação de professores e estudantes têm apontado, os problemas de acessos e ausência de acompanhamento de muitas crianças e adolescentes, são nos entendimentos docentes, os principais problemas para a reduzida, pouca ou até desistência. Este tópico teve 26 respostas aproximadas, abordando a exclusão, não participação devido os problemas com a internet, assim como, a falta de apoio com os recursos tecnológicos. Como demonstram algumas das respostas a seguir:

- " $\quad$ "A exclusão dos alunos que não possuem meios para acesso."

- "Valorização por parte dos familiares da educação das crianças."

- $\quad$ "Alunos sem acesso adequado a internet e equipamentos limitados (antigos, pouca memória) para a transmissão das aulas."

- $\quad$ "A realidade de alunos em relação ao acesso à tecnologia, acarretando a infrequência e não realização das atividades."

- $\quad$ "Rede de internet fraca dos discentes, participação efetiva nas discussões, falta de equipamentos para discentes e exposição diária nas telas."

- $\quad$ "A internet... Como os alunos não residem na cidade, o sinal fica comprometido para algumas aulas síncronas e resolução de avaliação."

- "Os pais buscarem as atividades."

- " "Falta de apoio institucional para recursos tecnológicos para professores e alunos."

- "Encontrar as famílias, promover propostas que possam ser realizadas em casa, receber as devolutivas, atender remoto e presencial ao mesmo tempo."

- "Alguns alunos possuem dificuldades tecnológicas."

Como visto, 48,2\% destacam a falta de acesso, problemas com a internet e muitos estudantes não possuirem equipamento ou possuir precariamente, ou ainda, não saberem utilizar os dispositivos, programas e plataformas.

Sobre a formação continuada, atuação docente, recursos materiais e imateriais tiveram 11 respostas (20,4\%), sendo evidenciado "Manter o alunato motivado $e$ proporcionar o mesmo nível de aprendizado do ensino presencial." Ou ainda, "Compreensão de que esse formato requer novas estratégias para que o ensino e a aprendizagem aconteçam.", "Pouca interação dos estudantes, fadiga com o excesso de atividades extra aulas, pouco domínio das novas tecnologias da informação $e$ comunicação, etc."; os demais, destacaram a necessidade de melhorar a interação com os alunos, o contato, a necessidade de conhecer outras formas para "motivar", a administração do tempo docente diante das telas, as complicações com a internet e um citou a organização da rotina em família. 


\section{- Questão 2}

A respeito do aproveitamento das aulas no ER, as aproximações foram organizadas em quatro possibilidades que mais apareceram: 1) Com prejuízo e aproveitamento baixo; 2) Poderia ser melhor se tivesse condições estruturais; 3) Bom aproveitamento; 4) Não conseguem avaliar. Sendo que outras/os (5) destacaram que, “... as atividades são desenvolvidas, na grande maioria, pelos pais”, ou ainda, apesar do baixo número nas participações e/ou acessos, o ER " [...] tenta suprir a falta que a sala de aula faz. No entanto, as desigualdades entre as redes pública e privada ficaram bem mais latentes.", outra/o reforça que "sinto que deixamos para trás as crianças com pouco acesso à internet ou de famílias com baixo nível de instrução." E de que foi pensado apenas para não perder o ano letivo, e que "deve ser aproveitado $e$ valorizado."

As/os que destacaram que o ER tem prejuízo e aproveitamento baixo, computou 20 respostas (37\%), destas apareceram expressões como "Muito prejuízo" e "pouco aproveitamento", sendo ainda destacado que, dependendo do contexto, chega a ser mínimo, "quase zero, principalmente quando se trata das famílias mais pobres e sem instrução.".

- "O aproveitamento é bem mais abaixo do que na aula presencial, no entanto, os alunos que se esforçam têm um rendimento razoável."

- " "Aproveitamento abaixo da média, porém o Ensino Remoto é necessário."

- "O aproveitamento é baixo, muitos estudantes não se adaptaram ao novo formato de aulas. Outra parcela não conseguiu acessar as plataformas por diversos motivos."

- "O aproveitamento virá do fato por termos mantidos contatos com os estudantes. Os mais dedicados e que tenham recursos disponíveis, poderão ter aproveitamento, mas os que não são dedicados e não têm recursos adequados, terão muitos prejuizos."

- "O aproveitamento se dá só pelos alunos com interesse. Os que não têm, se no presencial ainda faziam, no remoto utilizam de desculpas pra não realizar."

- Colheremos os frutos desse ensino, que não alcança a todos os alunos, no futuro. Sérias deficiências de aprendizagem.

- $\quad$ Para conteúdo teórico, considero que o aproveitamento é alto por alunos que se interessam pela disciplina e baixíssimo pela maioria dos alunos. Há dificuldade para identificar e dar atenção aos que estão perdidos nas aulas. Para o conteúdo prático, o dano é gigantesco, um abismo para a formação profissional. Os alunos estão progredindo sem conhecimento e sem a experiência proporcionada pelas aulas práticas e interações sociais.

- $\quad$ Sinceramente, acho que $40 \%$ do que é passado pode ser aproveitado. 
Muito do que foi dito responsabiliza o 'aluno com falta interesse', porém é preciso refletir sobre os percursos teórico-metodológicos que temos proposto aos estudantes no ER, é uma repetição das aulas presenciais, só que em tela? Ou temos proposto atividades mais ativas e que desafiam os estudantes além da escuta das exposições nas plataformas? Estas são questões que precisamos refletir e agir.

O tópico seguinte, de que poderia ser melhor se tivesse condições estruturais, considerado “mediano", obteve 10 respostas (18,5\%). Dentre estas, a de que "Quando tem ajuda dos pais, os alunos acompanham o ensino e aprenderam a estudar em casa", ou ainda, "Para que o aproveitamento seja efetivo acredito que seja necessário o entendimento desse novo formato e das grandes dificuldades que ele acarreta." E que um dos principais motivos é a exclusão digital dos estudantes.

O terceiro, destacou o "Bom aproveitamento", com 15 respostas aproximadas $(27,8 \%)$. Destacando que existem "ferramentas" para que seja possível promover o “um bom andamento dessas aulas.”, quanto são proveitosas e positivas.

- “É um processo que precisa ser pensando e estabelecer critérios mais claros para que isso aconteça. Vejo acontecendo o "aproveitamento" de estudos que nem sequer foi realizado uma ação concreta com os estudantes."

- " "Acredito que os que estão acompanhando as aulas conseguem alguma coisa."

- "Considero razoável. Mas ainda estou investigando isso."

- $\quad$ "Depende de muitas variáveis emocionais e sociais, que vão além da aula em si, mas para aqueles que mantêm o foco, pode-se avaliar em $60 \%$ de aproveitamento."

- $\quad$ "Quem acessa a aula online está conseguindo acompanhar como se fosse presencial, quem está somente com material impresso está com grande defasagem."

- $\quad$ "Para se ter um bom aproveitamento das aulas no ensino remoto é preciso reciclagem metodológicas e tecnológicas, além de muito esforço tanto na preparação das aulas como na execução, mantendo o nível de interesse alto entre os alunos. Tenho conseguido um bom aproveitamento por meio de desafios e atividades mais leves, com bastante interatividade."

- $\quad$ "Temos alunos que se saem muitíssimo bem nesta modalidade"

Entre os respondentes, 4 (7,5\%) destacaram que é difícil avaliar com precisão, os problemas de participação por muitos fatores:

- “... talvez por timidez, não se envolvem como também é difícil avaliar à distância, pois não dá pra saber se o aluno conseguiu aprender de fato ou se pesquisou para responder às avaliações."

- "Penso que ele funciona, mas precisa de avaliação constante sobre a prática Pedagógica, metodologias aplicadas, relação professor x aluno." 
- "Difícil de avaliar pois de fato não sabemos se foi pelo aluno ou por outra pessoa que o auxiliou, mesmo se for para avaliar algumas atividades de forma síncrona, solicitando que o aluno se posicione, ele pode estar falando lendo algum papel e não quer dizer que seja de fato a aprendizagem dele, enfim, é difícil. “

\section{- Questão 3}

A questão sobre a experiência com aulas remotas, foi destacada nos seguintes tópicos: 1) Um processo novo que exigiu adaptação, que foi difícil, mas possível; 2) Angustiante e desgastante; e, 3) Desafiadora e com muitas aprendizagens. Para 10 $(18,5 \%)$, foi um processo que exigiu adaptação. Para uns foi "novo" e "dificil no inicio”. Como afirmam:

- "A princípio assustadora, pois de imediato foi preciso buscar equipamentos, estratégias para que as aulas fossem produzidas e válidas."

- "Me sinto cansada, porém satisfeita com o trabalho que venho desenvolvendo, pois tenho buscado de várias formas, com várias alternativas e estratégias levar o aprendizado e o conteúdo das disciplinas que ministro para meus alunos."

- "Válida, porém considero as aulas presencias muito mais proveitosas."

- "Momento de adaptação e, felizmente, quem possui uma equipe disposta, consegue realizar um trabalho dinâmico com resultados positivos."

Outros 10 (18,5\%), consideraram como "Angustiante e desgastante", com rendimento comprometido, até "ruim" e "péssima".

- $\quad$ "Por causa de minha vivência com a tecnologia tenho conseguido superar as barreiras impostas à nova modalidade, embora acho mais desgastante que o presencial, ao mesmo tempo fico triste que o sistema não contempla a todos os alunos."

- $\quad$ "Tem sido muito difícil, principalmente dentro do contexto da educação especial, trabalhar com os alunos desse público tem sido um desafio, uma vez que carece de um acompanhante mais efetivo e de um diálogo mais permanente entre a família e a escola, algo que era para estar acontecendo, nesse momento de forma efetiva e em muitos casos não está."

- "Extenuante, custosa em tempo e no financeiro, desafiadora. Aprendizados diversos e emoções as mais conflitantes possíveis."

- $\quad$ "Tivemos que aprender sozinhos como conduzir as aulas remotas. Foi frustrante não termos recebido capacitação, treinamento e incentivo da secretaria de educação."

- "É uma experiência imposta a todos sem muito preparo e que ainda estamos aprendendo a lidar."

- "Já tinha experiência anterior, só que o material era preexistente ou criado antes do curso iniciar. A experiência com EF fundamental está sendo bem trabalhosa, resultando em sobrecarga que está afetando vista e coluna."

O último tópico foi uma surpresa, pois a maioria, 31 (57,5\%), a classifica como desafiadora e com muitas aprendizagens, até "inovadoras", como definiram dois (2) 
docentes. Difícil reduzir numa análise, pois as considerações docentes são muitas, como, por exemplo, o desenvolvimento de "habilidades como mídias digitais" e tecnologias, até "exaustiva, porém, rica”. Embora, afirmem que não substitui o "contato presencial".

- “Uma nova aprendizagem de fazer o remoto acontecer. É possível trabalhar de forma presencial e remota quando necessário. Apesar dos estresses."

- "A experiência obtida é muito valiosa, devido ao necessário desenvolvimento profissional no uso de novas tecnologias. Apesar disso, sinto muito a falta do contato presencial com os alunos, e creio piamente que essa distância de certa forma é prejudicial."

- "Proveitosas, mas quando o estudante não tem auxílio dos pais ou não possui internet, fica complicado."

- $\quad$ "Eu particularmente gosto de dar aula nesse formato, porém vejo que não consigo alcançar todos os alunos, o que me preocupa."

- "Boa. Minha experiência em aulas, no contato com os alunos, é exitosa. Só não é ótima pela não presença. Gosto do ensino remoto em parte, mas o silêncio durante a aula, a falta do olho no olho me incomoda."

- $\quad$ "Na área de artes tem sido interessante aprofundar novas possibilidades e associar os recursos digitais com diversas produções de artes, no entanto, extremamente desafiador a dificuldade de acesso aos recursos por boa parte dos alunos, inclusive a internet que seria o básico, e também outras práticas que exigiria orientação aproximada ou produções coletivas terem sido abortadas."

- $\quad$ "Como um grande desafio, pois nunca havia feito esse tipo de ensino, me fez repensar a forma de ensinar e também em muitos casos me sinto perto dos meus alunos."

- "Experiência positiva. Tinha preconceito em relação ao ensino remoto, por causa do meu desconhecimento sobre as ferramentas de ensino e desatualização/desconhecimento sobre os métodos de aprendizagem ativa. Considero que estava no "tempo das cavernas" em relação ao ensino e a pandemia possibilitou essa releitura/entendimento sobre como ensinar."

- "Ótima, vou manter as ferramentas de aprendizagem quando retornar para sala de aula."

- $\quad$ "Minha experiência tem sido positiva, me sinto desafiada e dispondo de mais recursos tecnológicos para as aulas. Com mais liberdade e criatividade na hora de inovar e provocar os alunos com temas da atualidade. Sinto falta de mais interação entre os alunos e também me sinto muito cansada e estressada por acabar trabalhando muito mais horas em home office do que presencialmente."

- $\quad$ "Minha experiência tem sido positiva no sentido de organização e busca das famílias, exceto claro, pelas crianças que não consigo contato."

Ou ainda, $3(5,7 \%)$ que fizeram outras reflexões, como a 'não dificuldade'.

- "Edificante e ao mesmo tempo frustrante, pois tenho aprendido muito e melhorado significativamente minhas aulas, porém apenas cerca de $30 \%$ dos meus estudantes estão vivenciando isso. Além disso, é bem difícil não ter os equipamentos adequados e bem custoso tentar suprir essa falta de infraestrutura e essa inadequada condição de trabalho."

- "O que fazemos hoje, buscamos nosso aprimoramento sozinhos". 
Esse mapeamento hermético dos discursos selecionados por aproximação nos confirma muitas das questões que vivenciamos diariamente e precisam estar no centro das discussões das instituições e profissionais da educação, salvaguardando que a responsabilidade tem sido posta aos docentes, os quais como afirmam, têm reinventado as próprias práxis. Entretanto, não podemos esquecer e/ou negligenciar os muitos que não têm acessos, cujas consequências ainda desconhecidas é de atraso, exclusão e deficit a ser mensurado das perdas e atrasos nas aprendizagens dos estudantes, esta é uma responsabilidade e compromisso de todos.

\section{O atual cenário da educação e construção de novas/outras experiências}

O ensino remoto na pandemia impôs às instituições de ensino, seja no âmbito privado ou público, básico ou superior, conforme mencionado anteriormente, o uso de vários equipamentos tecnológicos (como computadores, tablets e smartphones), bem como o uso de dispositivos tecnológicos que serviram de medium para que as aulas fossem transmitidas.

O manuseio dessas plataformas e aplicativos, apesar de ainda estarem em fase de apropriação e de aprendizagem para docentes e discentes, já demonstra que estamos num percurso sem retorno, no sentido de que o trabalho e desenvolvimento das aprendizagens que até agora foram elaborados e construídos a custo de muito esforço, não poderão ou deverão ser desprezados, descartados. Afinal, as práticas que conseguiram tornarem-se exitosas foram realizadas por docentes que compreendem a importância de dar continuidade à educação, ainda que remotamente. E foi dispondo de equipamentos, acesso à internet e domínio de tecnologias, na grande maioria, insuficientes e precários, que muitas atividades se consolidaram como "exitosas $e$ significativas".

A eficiência e o alcance dos ER's ainda não podem ser dimensionados, visto que a pandemia prossegue em ritmo cruel e letal, apesar da vacinação ter iniciado, vale salientar, a passos lentos. Desta forma, só poderemos ter uma avaliação mais exata das possíveis contribuições e dos impactos, positivos ou negativos, que essas experiências trarão na vida da comunidade escolar, especialmente, entre os discentes e docentes, após 
o término e/ou superação desta, e consequentemente, o 'esperado' retorno das aulas presenciais.

No entanto, é importante ressaltar que muitos desses resultados podem ser diretamente afetados por ações institucionais do Estado, que sejam voltadas para o planejamento e implementação de uma educação inclusiva e de qualidade. Que seja garantido, entre os vários direitos anunciados pela Carta Magna, o descrito em seu artigo $5^{\circ}$, parágrafo $\mathrm{XIV}^{11}$ : “é assegurado a todos o acesso à informação[...]” que hoje, pode ser claramente entendido como o direito ao acesso de internet, pois a falta deste representa alienação e exclusão, as quais podem afetar os cidadãos e as instituições, paralisando-as no tempo. Como destaca Citelli,

De outro lado, a escola como unidade marcada por configuradores institucionais desenvolvidos segundo outra lógica temporal, com os seus ritos e a convivência com o tempo lento, necessário aos processos de (in)formação, sistematização, maturidade reflexiva, vínculos com o conhecimento, etc.[...] E, para tanto, impõem-se, ainda seguindo a já citada metáfora nietzschiana da tranquilidade, certa lentidão incompatível com o estreitamento do tempo presente, aquele no qual a escola precisa realizar a sua operação formativa. (2016, p. 16)

O ER continuará desafiando o docente a novas/outras práticas pedagógicas, que inclusive, estão relacionadas a um Ecossistema Educomunicativo (SOARES, 2011), o qual usa como input e telos de referência a cultura digital, coloca o estudante como sujeito ativo e, consequentemente, responsável por sua aprendizagem.

Este formato de ensino evidenciou claramente, as várias fragilidades que interferem na educação, e não é de agora. Embora Citelli tenha destacado em 2016, suas palavras continuam atuais em 2021.

Nesse descompasso, podem ser localizadas algumas das várias fragilidades que matizam o sistema escolar brasileiro, cuja tradução pública, muitas vezes espetacularizada pela mídia, traduz-se nas críticas ao currículo à defasagem dos programas de ensino, ao despreparo dos professores, à leniência das autoridades governamentais, ao acesso de milhões de jovens das classes populares ao ensino público, à tibieza nas avaliações, ao paternalismo, ao abastardamento do que teria possuído nobreza no passado, para ficarmos em itens de uma lista infindável. (2016, p. 16)

\footnotetext{
11 https://www.senado.leg.br/atividade/const/con1988/con1988_15.12.2016/art_5_.asp Acesso em 20 de jun de 2021.
} 
As fragilidades supramencionadas, nos indicam os caminhos que precisamos trilhar para combatê-las. Não será possível nos adequarmos ao presente, sem que abandonemos preconceitos tecnológicos e estejamos dispostos a aprender por meio de formações que devem ser ofertadas pelo Estado para os usos críticos e mais 'adequado' de certas tecnologias e mídias digitais.

As escolas precisam ser estruturadas para determinadas práticas, como salas de informática onde os computadores funcionem adequadamente, acesso à internet, projetos que envolvam as tecnologias e a interpretação crítica às informações. $\mathrm{O}$ ensino precisa ser 'contemporanizado', por assim dizer, acompanhar o mundo num processo evolutivo e de inclusão educacional. Assim, as práticas exitosas podem ser multiplicadas e o ensino desenvolver-se de forma mais eficiente e, quem sabe, com menos desgastes para/entre os docentes e discentes.

\section{Considerações Finais}

É recorrente ouvir das(os) professoras(es), seja em contextos da educação básica como do superior, que as demandas do trabalho remoto superam e muito, as exigências formativas, laborais e de tempos de acessos aos dispositivos tecnológicos e digitais, para a realização das atividades. Passado mais de um ano nesta saída emergencial de ER, o que vemos são políticas públicas reduzidas, quanto aos cuidados com as instituições, os segmentos de ensino, os docentes e os discentes, sobre as quais pode-se destacar, a priori, como ações 'no mínimo' questionáveis, uma vez que, vivemos diversas realidades contemporaneamente: a) o excesso de atividades através das telas (computadores, tablets e smartphones), que ultrapassam, e muito, uma coerência que possa ser considerada salutar diante das demandas que aparecem no cotidiano do trabalho docente; b) as condições materiais (equipamentos e meios para realização das atividades) e imateriais (suporte formativo e socioemocional) para efetivação das ações laborais; c) a acentuada emergência sanitária, que consolidou-se numa crise desconhecida pela população viva, de insegurança e ausências do estado.

Para compreender o cenário atual é preciso observar, ouvir, registrar e sistematizar as problemáticas que temos enfrentado com os ER's (no plural, pois são 
variados), as quais decorrem de um formato em que os professores têm se deparado sem uma apropriada formação inicial e continuada.

As problemáticas supramencionadas agregaram ainda, a dificuldade que a própria educação tem em nunca conseguiu incluir o uso mais crítico e efetivo das mídias e tecnologias nos contextos. Estes, tendo os dispositivos digitais como uma das alternativas/meio para a superação da 'barreira 'que a pandemia impôs, uma vez que, somente pudemos dar continuidade aos ensinos, remotamente para parte da população estudantil, através das redes de internet, com o uso de plataformas e aplicativos, utilizados anteriormente, afim de entreter, como é o caso do WhatsApp e das redes sociais. A saída encontrada é, ao mesmo tempo, um desafio de formação e de ação profissional para conhecer mais e assim, promover uma educação que 'minimamente' chegue às maiorias, objetivo que sequer foi alcançado e, no entendimento deste estudo, pouco discutido e questionado.

Por fim, aula flui no ER? As tentativas são muitas, mas não suficientes ao acesso das maiorias.

\section{Referências}

BRASIL. Parecer CNE/CP n 5/2020 - Reorganização do Calendário Escolar e da possibilidade de cômputo de atividades não presenciais para fins de cumprimento da carga horária mínima anual, em razão da Pandemia da COVID-19. Brasília: MEC, 2020. In:

http://portal.mec.gov.br/index.php?option=com_docman\&view=download\&alias $=1451$ 1 -pcp005-20\&category_slud=marco-2020-pdf\&Itemid=30192. Acesso em 10 de jun de 2021.

BRASIL. LEI No 14.040, DE 18 DE AGOSTO DE 2020. Estabelece normas educacionais excepcionais a serem adotadas durante o estado de calamidade pública reconhecido pelo Decreto Legislativo $\mathrm{n}^{\circ}$ 6, de 20 de março de 2020; e altera a Lei $\mathrm{n}^{\circ}$ 11.947, de 16 de junho de 2009. Brasília: MEC, 2020. In:

https://www.in.gov.br/en/web/dou/-/lei-n-14.040-de-18-de-agosto-de-2020-272981525. Acesso em: 10 de jun de 2021.

BRASIL. CARTA MAGNA. Constituição (1988). Constituição da República Federativa do Brasil. Brasília, DF: Senado Federal: Centro Gráfico, 1988. In: http://www.planalto.gov.br/ccivil_03/constituicao/ConstituicaoCompilado.htm. Acesso em: 04 de ago. de 2021 
CIAN, Diega Orlando. Metodologia della ricerca pedagogica. Brescia, Italia: Editrice Scuola, 1997.

CITELLI, Adilson. Comunicação e Educação: o problema da aceleração temporal. In: NAGAMINI, Nagamini (organizadora). Questões teóricas e formação profissional em comunicação e educação. Ilhéus, BA: Editus, 2016. p. 11-23.(Série Comunicação e Educação; v. 1).

GADAMER, Hans Georg. Verità e Metodo. XIII edizione. Milano, Italia: Studi Bompiani: 2001.

SOARES, Ismar de Oliveira. Educomunicação: um campo de mediações. In:

CITELLI, Adílson; Castilho, Maria Cristina. Educomunicação: Construindo uma nova área de conhecimento. São Paulo: Paulinas, 2011.

TELES, Edilane C. Entre o dizer e o fazer com as mídias e tecnologias na formação inicial do pedagogo. 2019. Tese (Doutorado em Ciências da Comunicação) - Escola de Comunicação e Artes da Universidade de São Paulo. 2019.

TELES, Edilane C.; CAMPANA, Adriana Maria de A.; NASCIMENTO, Fabiana; COSTA, Suéller. O Ensino Remoto e os impactos nas aprendizagens. In: Políticas da vida. ComSertões, v.9, $\mathrm{n}^{\circ}$ 2, 2020. p. 1.18. In:

https://www.revistas.uneb.br/index.php/comsertoes/article/view/10091, Acesso em 20 de jun de 2021. 